\title{
Estimated Date of Conception
}

National Cancer Institute

\section{Source}

National Cancer Institute. Estimated Date of Conception. NCI Thesaurus. Code C120833.

An approximate calculated date at which the conception event took place. 